\title{
Üstün Yetenekli Öğrencilere Yönelik GeoGebra Destekli Etkinlik Hazırlamak İçin Yürütülen Tasarım Tabanlı Araştırma Sürecinden Yansımalar ${ }^{1}$
}

\author{
Reflections from a Design Based Research Preparing GeoGebra Supported Activities towards
} Gifted Students

\author{
Serdal BALTACI ${ }^{2} \quad$ Avni YILDIZ $^{3} \quad$ Yasemin KIYMAZ $^{4} \quad$ Cahit AYTEKIN $^{5}$
}

Başvuru Tarihi: 08.08.2016

Yayına Kabul Tarihi: 05.09.2016

DOI: $10.21764 /$ efd.12232

\begin{abstract}
Özet: Yapılan çalışmalar incelendiğinde Türkiye'de tasarım tabanlı araştırma üzerine çok az çalışma yapıldığı görülmektedir. Bunun yanında, üstün yetenekli öğrencilerin yaşıtlarına göre farklı becerilere sahip olduğu ve bu becerilere uygun etkinlikler hazırlamanın da kolay olmadığı bilinen bir gerçektir. Bu nedenle araştırmanın amacı, üstün yetenekli öğrencilere yönelik etkinlikler hazırlamak için BİLSEM (Bilim ve Sanat Merkezi) matematik öğretmenleri ile yürütülen tasarım tabanlı araştırma yöntemi sürecini yansıtmaktır. Böylece araştırmaya katılan üstün yetenekli öğrencilerin dersine giren BİLSEM matematik öğretmenleri ile etkinlik geliştirme ve üstün yetenekli öğrencilere uygulanması süreci ortaya çıkarılarak, üstün yetenekli öğrencilerin gereksinimlerine yanıt verebilecek etkinliklerin oluşması için bir örnek teşkil edecektir. Özel durum çalışması yönteminin kullanıldığı araştırmanın katılımcılarını, üç BİLSEM matematik öğretmeni ve altışar kişilik iki gruptan oluşan on iki üstün yetenekli öğrenci oluşturmaktadır. BİLSEM matematik öğretmenleri ve araștırmacıların birlikte hazırlamıs oldukları etkinlikler ilk gruba uygulanmış ve sonrasında gerekli revizeler yapılarak ikinci gruba uygulanmıştır. Sonuç olarak, en son revize edilen etkinlik sayesinde ikinci gruptaki üstün yetenekli öğrencilerin istenilenleri hem kağıt kalem ortamında, hem de GeoGebra yazılımını kullanarak keşfettikleri ve sonuca ulaştıkları gözlenmiştir. Ayrıca üstün yetenekli öğrencilere etkinlikler hazırlanmasının kolay bir süreç olmadığı sonucuna ulaşılmış, etkinlik hazırlanmasında tasarım tabanlı araştırma yönteminin potansiyelinin kullanılabileceği önerilmiştir.
\end{abstract}

Anahtar Kelimeler: BILLSEM matematik öğretmenleri, tasarım tabanll araştırma yöntemi, üstün yetenekli ögrenciler.

\begin{abstract}
A few studies were conducted on the issue of design experiment in Turkey when the studies were reviewed. Also, it is obvious that gifted students have different skills compared to their coevals and it is not easy to prepare activities appropriate for these skills. For this reason, the purpose of the study reflects the process of design experiment method conducted with BİLSEM mathematics teachers in order to prepare activities for gifted students. Therefore, an opportunity will be created for the formation of activities responding the needs of gifted students by revealing the process of developing and applying the prepared activities with BILSEM mathematics teachers giving courses to gifted students participating the study. The sample of the research in which the case study method was used consists of 3 BİLSEM mathematics teachers and 12 gifted students as two groups each involving 6 gifted students. The activities prepared by the BİLSEM teachers and the researchers applied to the first group then applied to the second group after the necessary revisions. As a result, the gifted students in the second group can discover and get results both in paper-pencil environment and by using GeoGebra software by means of the latest revised activity deveoped by desing-based research which is conducted with researchers and teachers. We have also concluded that there is not an easy process to prepare activities for gifted students. It has suggested that the potential of designbased research method can be used for preparing activities for gifted students.
\end{abstract}

Key Words: Mathematics teachers of gifted students, design based research, gifted students.

\footnotetext{
${ }^{1} \mathrm{Bu}$ çalışma Ahi Evran Üniversitesi Bilimsel Araştırma Projeleri Koordinasyon Birimince Desteklenmiştir. Proje Numaras1: EGT. A3. 16. 002

${ }^{2}$ Yrd. Doç. Dr., Ahi Evran Üniversitesi, Eğitim Fakültesi

${ }^{3}$ Yrd. Doç. Dr., Bülent Ecevit Üniversitesi, Ereğli Eğitim Fakültesi

${ }^{4}$ Yrd. Doç. Dr., Ahi Evran Üniversitesi, Eğitim Fakültesi

${ }^{5}$ Dr., Ahi Evran Üniversitesi, Eğitim Fakültesi
} 


\section{Giriş}

Üstün yeteneklilik kavramı, birçok araştırmacı tarafından farklı tanımlanmış ve farklı şekilde açıklanmaya çalışılmıştır. Üstün yetenekliler, bütün insanlarda bulunan özelliklerin dağılımı, sıklığı, zamanlaması ve kompozisyonu açısından farklılık gösteren kişilerdir (Akarsu, 2001). Araştırmalara göre matematik derslerinde üstün yetenekliler ise problemlerin çözümünde yaratıcılığını ortaya koyan bireyler olarak tanımlanmaktadır (Miller, 1990; Yıldız, Baltacı, Kurak \& Güven, 2012). Ayrıca Sowell, Zeigler, Bergwell ve Cartwright (1990) matematiksel alanda üstün yetenekli öğrencilerin, kendinden yaşça büyük öğrencilerin yapabildiği matematiksel becerileri sergilediğini belirtmiştir. Ancak hızlı problem çözmek ya da sembolleri ve formülleri ezberlemek, matematik dersi için üstün yeteneğin göstergeleri arasında değerlendirilmemektedir (Wieczerkowski, Cropley \& Prado, 2000).

Üstün yetenekli öğrenciler, öğrenme ortamında çeşitli araç ve gereçlere ihtiyaç duyabilirler. Ancak üstün yetenekli öğrencilerin eğitimi için kullanılacak araçların seçimi veya geliştirilmesinde onların yaratıcılıklarını ortaya çıkarabilecek çeşitli özelliklerin göz önünde bulundurulmasının önemli olduğu söylenebilir. Bu bağlamda kullanılabilecek araçlardan biri GeoGebra yazılımı olabilir. GeoGebra; giriş alanı, cebir alanı, cebir penceresi, grafik penceresi ve hesap çizelgesi görünümü ile matematiksel semboller, grafikler ve elde edilen değerlerin tabloya aktarımını dinamik bir süreçte gerçekleştirir. Bu durum GeoGebra'yı diğer dinamik geometri yazılımları ve bilgisayar cebiri sistemlerinden ayırmaktadır (Aktümen, Horzum, Yıldız \& Ceylan, 2010). Yapılan çalışmalar üstün yetenekli öğrencilerin eğitiminde GeoGebra yazılımının kullanılmasının yararlı olduğunu göstermektedir (Baki, Yıldız \& Baltacı, 2012; Aydos, 2015). Aynı zamanda GeoGebra yazılımı, öğrencilerin üst düzey düşünme becerileri sergilemesine yardımcıdır (Edward \& Jones, 2006). Fakat bunun için hem öğrencilerin öğrenmesini, hem de öğretmenlerin anlatımını kolaylaştıracak çeşitli öğrenme ortamlarının oluşturulması gerekmektedir (Baltac1, 2014). Bu öğrenme ortamlarında üstün yetenekli öğrencilerin gereksinimlerine uygun etkinliklerin hazırlanmasında yararlanılabilecek yöntemlerden birisi de tasarım tabanlı araştırma yöntemi olabilir. $\mathrm{Bu}$ görüşlere uygun olarak bu araştırmada, üstün yetenekli ögrencilerin gereksinimlerine uygun etkinlikler geliştirilirken öğrencilerin hem kâğıt kalem ortamında, hem de ihtiyaç duymaları halinde GeoGebra yazılımı ile keşif sürecine girebilmeleri için tasarım tabanlı araştırma (design experiment) yöntemi kullanılmıştır.

Tasarım tabanlı araştırma, kuramdan yola çıkarak öğretim stratejilerinin ve kullanılan araçların gerçek uygulama sürecinden elde edilen bulgulara göre süreç içinde yeniden revize edilmesine dayalı yeni bir araştırma yaklaşımıdır (Brown, 1992; Collins, 1992). Tasarım tabanlı araştırmaların en önemli özelliği bir yenilik üretiminde kullanılmasıdır. Bu yenilik bir kuram, yeni bir öğrenme ortamı ya da yeni bir eğitim uygulaması olabilir. Tasarım tabanlı araştırmayı, geleneksel deneysel araştırmalardan ayıran en önemli özelliği, iki farklı öğretim yöntemi uygulayıp hangisinin başarıyı daha çok arttırdığına bakmak yerine bir öğretim yöntemini süreç içinde en verimli hale getirmek için nasıl revize edilmesi gerektiğine odaklanmasıdır (Kuzu, Çankaya \& Mısırlı, 2011). Fakat tasarım tabanlı araştırma yapmanın bazı zorluklarından ve eğitim araştırmacıları tarafından çok fazla tanınmamasından dolayı bu yöntemi kullanarak yapılan yayın sayısı oldukça azdır (Collins, Joseph \& Bielaczyc, 2004).

Tasarım Tabanlı Araştırma Birliği (Design Based Research Collective, 2003) bu yöntemin kapsamlı bir şekilde tanımını yapan ilk topluluk olarak bilinmektedir. Bu topluluk daha önce literatürde kullanılan birçok isim arasından tasarım tabanlı araştırma (design based research) ismini kullanmayı tercih etmiş ve bundan sonra literatürde sıklıkla bu isim kullanılmıştır (Kuzu, Çankaya \& Mısırlı, 2011). Diğer taraftan yapılan çalışmalar incelendiğinde, Türkiye'de tasarım tabanlı araştırma (design based research) üzerine çok az çalışma yapıldığı tespit edilmiştir (Doğan \& Gürel, 2013; Kuzu, Cavkaytar, Çankaya \& Öncül, 2013; Kertil, Erbaş \& Çetinkaya, 2014; Yıldırım, 2014). Üstün yetenekli öğrencilerin yaşıtlarına göre farklı becerilere 
sahip olduğu bilinen bir gerçektir. Bu bağlamda onların ihtiyaçlarına uygun, GeoGebra yazılımının da kullanılabileceği etkinlikler hazırlamanın basit olmadığı söylenebilir. Bu nedenle araştırmanın amacı, üstün yetenekli öğrencilere yönelik etkinlikler hazırlamak için BİLSEM matematik öğretmenleri ile yürütülen tasarım tabanlı araştırma sürecini yansıtmaktır. Araştırmanın bu amacı, sürecin uzun olması nedeni ile bir etkinlik için yansıtılacaktır. Böylece araştırmaya katılan üstün yetenekli öğrencilerin dersine giren BİLSEM matematik öğretmenleri ile hazırlanan etkinliğin geliştirilmesi ve uygulaması süreci ortaya çıkarılarak, üstün yetenekli öğrencilerin gereksinimlerine yanıt verebilecek etkinliklerin oluşması için bir firsat oluşacaktır.

\section{Yöntem}

$\mathrm{Bu}$ bölümde; araştırmanın yöntemi, araştırmanın katılımcıları, uygulama süreci, verilerin toplanması ve analizi hakkında bilgiler verilmiştir.

Araştırmanın Yöntemi

Araştırmada, özel durum çalışması yöntemi kullanılmıştır. Bu yöntemde ortam, birey veya süreçler değerlendirilmekte ve ilişkiler araştırılmaktadır (Yıldırım \& Şimşek, 2008). Bu yöntem ile yürütülen araştırmalarda, belli bir grubun derinlemesine incelenmesi ve irdelenmesi esas olduğundan bu araştırmada da takip edilecek yöntemin özel durum çalışması yöntemi olduğuna karar verilmiştir.

Araştırmanın Katılımcıları

Türkiye'de üstün yetenekli öğrenciler, okul programlarından bağımsız olarak farklı bir eğitim kurumu olan Bilim ve Sanat Merkezlerinde (BILLSEM) eğitim görmektedirler. Bu merkezlerde eğitim görecek olan üstün yetenekli öğrencilerin seçim süreci altı aşamada gerçekleşmektedir. Bunlar sırası ile tanılama, aday gösterme, ön değerlendirme, grup tarama, bireysel inceleme ve kayıtt-yerleştirmedir (Bilsem Yönerge, 2007). Bilim ve Sanat Merkezlerinin öğrenci alırken bu aşamaları göz önüne alması Türkiye'nin üstün yetenekli öğrencilerin seçilmesi konusuna önem verdiğini gösterebilir.

Araştırmada, katılımcıların belirlenmesinde amaçlı örneklem yöntemlerinden maksimum çeşitlilik örneklemesi kullanılmıştır. Maksimum çeşitlilik örneklemesinde amaç, göreli olarak küçük bir örneklem oluşturmak ve bu örneklemde çalışılan probleme taraf olabilecek bireylerin çeşitliliğini maksimum derecede yansıtmaktır (Creswell, 2005; Johnson \& Christensen, 2004). Bu bağlamda araştırmanın katılımcılarını; üç BİLSEM matematik öğretmeni, dört araştırmacı ve Bilim ve Sanat Merkezi'ne devam etmekte olan her bir grupta altı öğrenci olmak üzere toplam 12 üstün yetenekli 10. sınıf öğrencisi oluşturmuştur. Birinci grupta iki kız dört erkek, ikinci grupta ise üç kız üç erkek öğrenci bulunmaktadır. Üstün yetenekli öğrencilerin çoğu, Bilim ve Sanat Merkezi'ne altıncı sınıfta devam etmeye başlamış olup yaklaşık beş yıldır bu merkeze devam etmektedirler. Araştırmaya katılan üstün yetenekli öğrenciler seçilirken ise, BİLSEM öğretmenlerin görüşleri doğrultusunda GeoGebra yazılımını kullanma becerisine ve farklı başarı düzeyine (yüksek, orta, düşük) sahip öğrenciler almaya dikkat edilmiştir. Araştırmaya katılan BILLSEM matematik öğretmenlerinin üçü de erkektir. Öğretmenlerin biri yaklaşık 8 yıldır, diğer ikisi de 5 yıldır Bilim ve Sanat Merkezi’nde öğretmenlik yapmaktadır. Araştırmaya katılan üstün yetenekli öğrenciler 6'şarlı iki gruba ayrılmış, ilk gruba uygulanan ve revizeye uğrayan etkinlikler tekrar ikinci gruba uygulanmıştır.

\section{Veri Toplama Araçları}

Araştırmanın verileri; araştırmacıların BİLSEM öğretmenleriyle yaptığı görüşmelerin ses kayıtları, etkinliğin uygulanması esnasındaki çalışma ortamının video kayıtları, öğrencilerin tahtada yaptıkları çözümler ile GeoGebra ekranında yapılan modeller yoluyla toplanmıştır. 


\section{Uygulama Süreci}

Uygulamaya geçilmeden önce araştırmacılar, üstün yetenekli öğrencilerle yapılan çalışmaları incelemiş ve GeoGebra yazılımının süreçte kullanılabilecekleri etkinlikler tasarlanmasına karar vermiştir. Geliştirilmesiplanlanan etkinlikler, üç BİLSEM matematik öğretmeni ile paylaşılmış, ardından öğretmenlerin görüşleri doğrultusunda bu etkinliklerden birini seçerek etkinliği detaylandırarak revize etmişlerdir. Revize edilen etkinliğin uygunluğu ve uygulanabilirliğini, araştırmacılar ve BİLSEM matematik öğretmenleri tekrar bir araya gelerek tartışmışlardır. Ardından tekrar revize edilen etkinlik, üstün yetenekli 10. sınıf öğrencilerinin olduğu iki gruptan birine uygulanmıştır. Uygulamayı araştırmacılar yapmış ve öğretmenler bu süreçte sınıfta yapılan uygulamalarda yer almışlardır. Elde edilen sonuçlara göre araştırmacılar, BİLSEM matematik öğretmenleriyle tartışarak etkinliği tekrar revize etmiştir. Ardından etkinlik, araştırmanın ikinci grubuna uygulanmış ve gerekli değerlendirmelerin ardından son şekli verilmiştir. Bu süreçte ortam, öğrencilerin hem kâğıt - kalemi hem de GeoGebra yazılımını kullanabilecekleri şekilde tasarlanmıştır.

Çalışma başlamadan önce öğrencilerle bir süre vakit geçirilmiş ve araştırmanın amacı hakkında yüzeysel bilgiler verilmiştir. Her bir öğrencinin izinleri alınarak sınıf içerisinde video kaydı yapılmıştır. İlk gruba yapılan uygulamanın ardından etkinliklerin biraz uzun zaman alması ve öğrencilerin ders içerisindeki davranışları dikkate alınarak etkinlikler kısaltılmış ve ikinci gruba uygulanmıştır. Birinci gruba uygulanan etkinlikler iki ders, ikinci gruba uygulanan etkinlikler ise dört ders sürmüştür. Bu şekilde birinci gruba yürütülen her bir ders 60 dakika ikinci gruba ise her bir ders 30 dakika olarak planlanmış ve uygulanmıştır.

Etkinlikler, öğrencilerin kendilerini rahat hissedecekleri ve GeoGebra yazılımı ile çalışabilecekleri Bilim ve Sanat Merkezi'ndeki kendi sınıflarında yapılmıştır. Ayrıca uygulama boyunca öğrencilerin problem ile ilişkili olarak hem kâğıt kalem ortamında, hem de GeoGebra ekranında yaptıkları işlemler ve oluşturdukları modeller kaydedilmiştir.

\section{Verilerin Analizi}

Araştırmanın verileri, nitel veri analiz yöntemlerinden içerik analizi ile çözümlenmiştir. Bu nedenle yapılan çalışma boyunca araştırmacıların, BİLSEM öğretmenlerinin ve üstün yetenekli öğrencilerin görüşmeleri hem video hem de ses kayıt cihazı ile kaydedilmiştir. Toplanan veriler analiz edilmeden önce video ve ses kayıtlarının dökümü ve kontrolü yapılmıştır. Kayıtların dökümü yapılırken her konuşmanın duyulduğu şekliyle, hiçbir düzeltme yapılmadan ve konuşma sırasına dikkat edilerek yazılmasına önem gösterilmiştir. Diğer taraftan bulgular sunulurken araştırmacılar, BİLSEM öğretmenleri ve üstün yetenekli öğrencilere kodlar kullanılmıştır. Bu bağlamda; A, araştırmacı; B1, BİLSEM öğretmeni 1 ve Ü1 üstün yetenekli öğrenci 1 .....v.s. şeklindedir.

\section{Bulgular}

Bu bölümde üstün yetenekli 10. sınıf öğrencilerine yönelik tasarım tabanlı araştırma yöntemiyle GeoGebra yazılımı da kullanabilecekleri bir etkinliğin hazırlanması sürecinden yansımalar sunulmaya çalışılmıştır. Bulgular; araştırmacılar ile BİLSEM matematik öğretmenlerinin etkinlik oluşturma sürecindeki konuşmalarından ve etkinliğin uygulanması sırasında üstün yetenekli öğrenciler ile araştırmacılar arasında geçen diyaloglardan alınan doğrudan alıntılarla, öğrencilerin yaptıkları çözümlerle ve GeoGebra ekranında yapmış oldukları modellerle desteklenmiştir. Bu bağlamda, veriler incelendiğinde aşağıdaki bulgular tespit edilmiştir: 
Etkinliğin oluşturulması sürecinden yansımalar ve ilk revize;

Araştırmacılar, 10. sınıf kazanımlarına göre oluşturulabilecek bazı etkinlikler belirlemişler ve bu etkinliklerin uygulanabilirliği konusunda BILLSEM matematik öğretmenleriyle bir görüşme yapmışlardır. Görüşmede her öğrencinin fikir beyan edebileceği, merak uyandıran, keşfettiren, rutin problemlere benzemeyen ve sinıf içerisindeki işbirliğine uygunluk hususlarına dikkat edilmesinin önemli olduğu ifade edilmiştir. Bu sürece yönelik olarak BİLSEM matematik öğretmenlerinden B1 ve B2 öğretmeninin ifadeleri aşağıdaki gibidir.

B1: Öncelikli olarak yaptı̆̆ımız etkinliklerde üstün yetenekli ögrenciler hemen sonucu söyleme girişiminde bulunmamalıdır.

B2: Evet, bence de. Bu ögrenciler rutin problemlere benzeyen problemleri hemen çözerler. Yapılacak etkinliklerde ögrenciler hemen sonuca ulaşmamal, meraklanmalılar ve hepsi birlikte bir şeyler söyleyebilmelidir.

Ardından araştırmacılar tarafından belirlenen etkinlik taslakları, BILSEM matematik öğretmenleriyle tartışlarak uygun olan bir etkinlik belirlenmeye çalışılmıştır. Bu süreçte BİLSEM öğretmenleri, 10. sınıfa devam eden üstün yetenekli öğrencilere yönelik tasarlanan bazı etkinliklerin onların seviyesine uygun olmadığ 1 görüşü ortaya çıkmıştır. Bu süreçte BİLSEM matematik öğretmenleriyle yapılan görüşmelerde uygun olan bir etkinliğe yönelik olarak aşağıdaki görüşler ortaya çıkmıştır.

B1: Bence, geometrik ispat etkinliklerindense bir doğru parçasını bölen etkinlik üzerinde çalışsak daha güzel olabilir. Çünkü hem müfredatta var, hem de öğrencilerin daha fazla zorlandıkları konular arasında. Diğer etkinlikler içerisinde bu daha uygun.

B3: Bence de, B1 hocamın dediği gibi ögrenciler bu konuda biraz zorlanmakta. Bunun üzerinde çalışır ve buna yönelik bir etkinlik hazırlarsak ögrenciler daha fazla faydalanacaktır.

$\mathrm{Bu}$ süreçte üstün yetenekli öğrencilere uygulanacak ve yansıtılmaya çalışılacak etkinlik aşağıdaki şekilde olmuştur.

"Düzlemde $A(2,1)$ ve $B(8,1)$ noktaları veriliyor. $A B$ doğrusu üzerinde $\frac{|A C|}{|B C|}=\frac{1}{2}$ olacak şsekilde bir C noktasını nasıl belirlersiniz?"

BİLSEM matematik öğretmenleriyle yapılan görüşmeler neticesinde yukarıdaki gibi bir doğru parçasını bölen noktaların belirlenmesiyle ilgili etkinlik üzerinde çalışılmasına karar verilmiştir. Görüşme sonrasında bazı yönergeler eklenerek etkinlik, araştırmacılar tarafından dizayn edilmiştir. $\mathrm{Bu}$ süreçte araştırmacılar arasında geçen diyalog aşağıdaki gibidir.

A1: BİLSEM matematik ögretmenleriyle doğru parçasını bölen noktalar etkinliği üzerinde çalışmaya karar verdik. Burada öncelikli olarak yazdı̆̆ımı gibi A ve B noktalarını versek ve buradan faydalanarak sayllarla işleme başlasak. Sonrasinda bunun matematiksel genelleştirmesini isteyerek bu şekilde özelden genele doğru öğrencilerin formül bulmasını sağlayabilir miyiz?

A2: Olabilir. Evet, ama öncelikli olarak kendileri bir nokta belirlesinler. Yani biz, bir nokta vermeyelim.

A1: Olur. Noktalara göre matematiksel genelleştirmesine ulaşmalarını sağlamamız lazım. Sonrasında da köşselerinin koordinatlarına göre üçgenin ağırlık merkezinin koordinatlarını kendilerinin belirlemesini să̆layabiliriz. Bu şekilde ă̆ırlı merkezini de matematiksel olarak genelleş̧irebilirler. 
A4: Evet. Bu şekilde formül ezberlemekten de kurtulurlar ve formülü kendileri buldukları için daha güzel bir çalışma olabilir.

Yukarıdaki konuşmaların ardından etkinliğe şu şekilde yönergeler eklenmiştir.

"Herhangi iki $A\left(x_{1}, y_{1}\right)$ ve $B\left(x_{2}, y_{2}\right)$ noktası için $\frac{|A C|}{|B C|}=k$ olduğunda $A B$ doğrusu üzerinde istenilen C noktasını matematiksel olarak genelleştiriniz?"

"Köşe koordinatları $A\left(x_{1}, y_{1}\right), B\left(x_{2}, y_{2}\right)$ ve $C\left(x_{3}, y_{3}\right)$ olan bir üçgenin ağırlı merkezinin koordinatlarını belirleyiniz?"

Sonra araştırmacılar tarafından düzenlenen etkinlik, tekrar BILLSEM matematik öğretmenleriyle bir araya gelerek gözden geçirilmiş ve bu süreçte öğretmenlerin etkinliklerin yönergelerinde bazı değişikliklerin olabileceği görüşünü belirttikleri görülmüştür. Yapılması istenen bu değişiklikler sayesinde üstün yetenekli öğrencilerin farklı yönlerinin ortaya çıkabileceği fikri ortaya atılmıştır. Bu süreçte araştırmacılar ile BİLSEM matematik öğretmenleri arasında geçen diyalog ve etkinlikte sorulması gereken bir diğer husus aşağıdaki gibi gerçekleşmiştir.

B1: Şimdi biz burada öncelikli olarak bir doğru parçasını belli bir oranda bölen noktalara ait matematiksel genelleştirmelerini sağladık diyelim. Bence bunlardan sonra acaba ögrencilere istenilen bu noktanın dışarıda olması durumunda nasıl bir yol izleyeceklerini sorabilir miyiz?

A2: Olabilir aslinda neden bu şekilde düşündünüz hocam.

B1: Çünkü bunlarl rahatllkla yapabilir. Ayrlca daha önce sizin de belirttiğiniz gibi matematiksel genelleş̧tirme çok işlerine yarayacaktır. Ama bunlara bu noktanın doğru dışarısında olduğunda nasıl bir nokta olacağını sorsak belki daha güzel fikirler ortaya çıkabilir.

A1: Evet, bende hocama katıllyorum. Acaba o nokta bir üçgenin açıortayı olur mu? Veya başka bir durum deneyelim mi?

A2: Verilen iki noktaya uzaklıkları oranı $1 / 2$ olan noktayı $x$ ve y olarak aldiğımızda şu şekilde bir denklem çıtk. Bu denklemi GeoGebra ekranına yazalım. Evet, bakın bu nokta bir çember üzerinde geziniyor.

B1: Işte bu durumu belki tahmin edecekler, belki de yazllım ile istenilen noktanın çember üzerinde gezineceğini keş̧fedecekler.

Yukarıdaki şekilde gerçekleşen tartışmaların ardından etkinliğe şu sorunun da eklenmesi yönünde karar alınmıştır.

"Düzlemde herhangi iki A ve B noktaları veriliyor. $\frac{|A C|}{|B C|}=k$ olacak şekilde bir C noktasını nasil belirlersiniz?"

Diğer taraftan tasarım tabanlı çalışmalar ile BİLSEM öğretmenlerinin teknoloji kullanma isteklerinin daha da arttığı, bunun için öğretimlerini GeoGebra yazılımı ile şekillendirmeleri gerektiğini ifade etmiş̧lerdir. Bu süreci yansıtan B3 ve A2 arasında geçen diyalog aşă̆ıdaki gibidir. 
B3: Sizlerle birlikte düşündügümüzde bu şsekilde bir sonucun ortaya çıkmasını ilk başta düşünmemiştim. Mesela düzlemde aldı̆̆ımı dışarıdaki noktanın bir çember üzerinde gezdiğini yazıllım ekranında gözlemlememiz çok farklı bir etkinlik oldu.

A2: Siz daha önce GeoGebra yazılımını kullanıyor muydunuz?

B3: Bilgim var ama çok da kullanmıyordum. Fakat bu gibi durumlar beni daha çok kullanmaya itiyor.

Ayrıca BİLSEM matematik öğretmenlerinin; Bilim ve Sanat Merkezine alınan üstün yetenekli öğrencilerin eğitimlerinde ders saatlerinin başlama saatleri ve onlarla ilgilenme süreleri gibi olumsuz durumların teknoloji kullanım becerilerini etkilediğini ve bu yüzden bazı değişikliklerin olması gerektiğini vurguladıkları belirlenmiştir. Bu sürece ait B2 ve B3 öğretmenlerinin ifadeleri aşağıdaki gibidir.

B2: Aslında burada bizim yaşadiğımız olumsuzluklardan en önemlisi de öğrencilerin derslere başlama saatleri ve çıklş saatleri. Çünkü ögrenciler Bilim ve Sanat Merkezine okullardan sonra gelebilmekte ve akşam saatlerine kadar kalmaktadirlar. Bu durum da yorgunluklar ve kendilerini buraya ait hissetmemeleri gibi olumsuzlar ortaya çıkabilmektedir.

B3: Evet, aynı şeyler bizlerde de olabilmekte. Aslında burası kendi başına bir merkez ve buraya gelen ögrenciler de sadece buraya ait olsa o zaman çok daha farklı durumlar ortaya çıkabilir bence. Bu gibi durumlardan dolayı zaman sıkıntımız yaşanıyor ve teknoloji kullanmaya zamanımız bile kalmıyor aslında.

Birinci gruba ait uygulama süreci ve ikinci revize;

BİLSEM matematik öğretmenlerinin görüşleri ve araştırmacıların birlikte çalışmaları sonucunda revize edilen etkinlik, üstün yetenekli öğrencilerin oluşturmuş olduğu ilk gruba uygulanmış ve bu süreçte üstün yetenekli öğrencilerden gelen dönütler aşağıdaki gibi gerçekleşmiştir.

İlk olarak öğrencilerden uç noktaları verilen bir doğru parçasını belirli bir oranda bölen noktanın bulunması istenmiştir. Bu süreçte üstün yetenekli öğrenciler çok rahatlıkla istenileni yaparak tahtada da anlatmışlardır. Bu sürece ait olan şekil aşağıdaki gibidir.

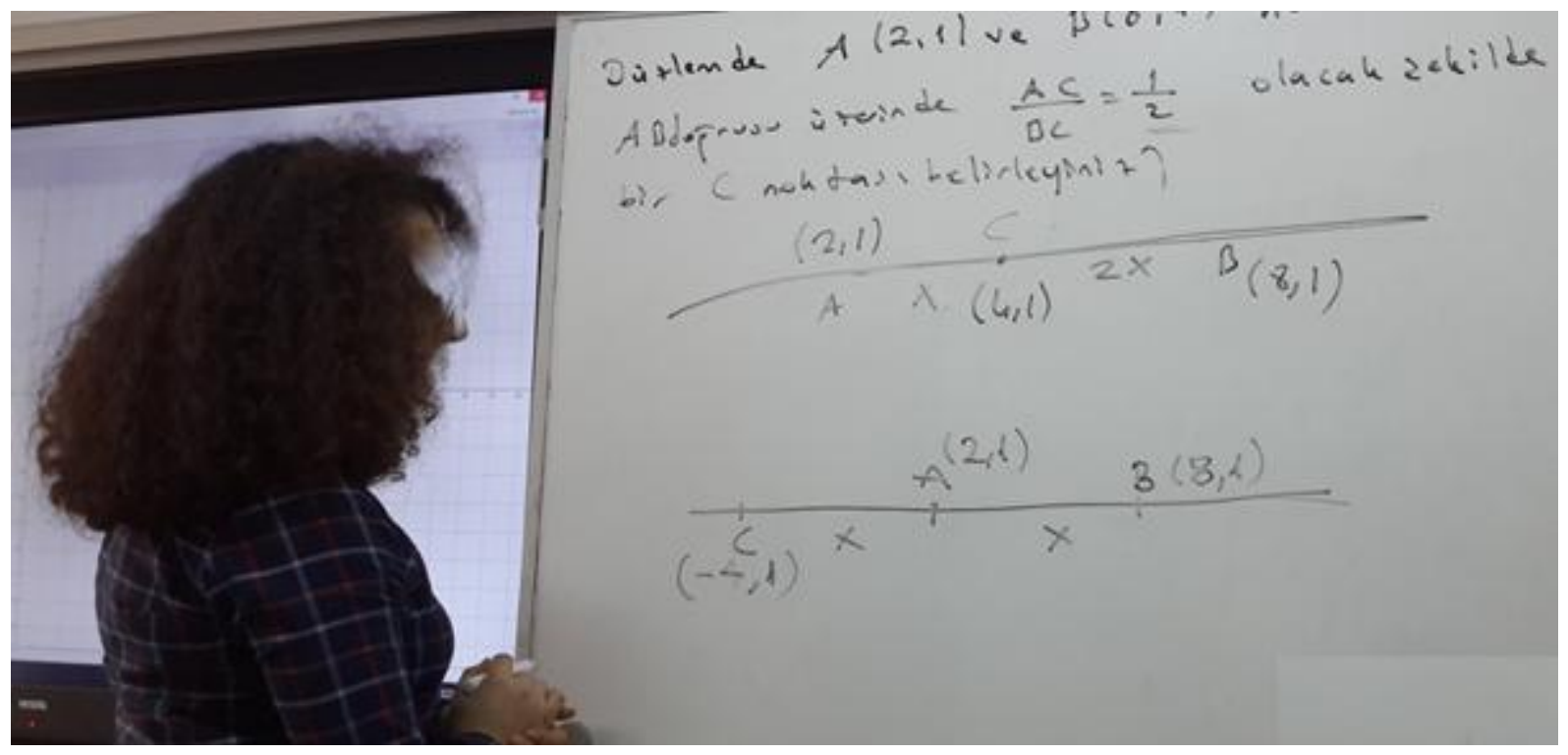

Şekil 1: İlk grubun tahtada istenilen noktayı bulmasına yönelik bir kesit 
Ardından üstün yetenekli öğrencilere, istenilen bu nokta başka nerelerde olabilir sorusu yöneltilmiştir. Bunun üzerine öğrenciler, istenilen noktanın dışarıda da olabileceğini ifade etmişlerdir. Araştırmacıların yönelttikleri "Nasıl?" sorusu üzerine bazı öğrencilerin üçgendeki açıortay ile ilişkilendirme yapmaya çalıştıkları görülmüştür. $\mathrm{Bu}$ sürece ait olarak bazı öğrencilerin yapmış oldukları şekillerden bir kesit aşağıdaki gibidir.

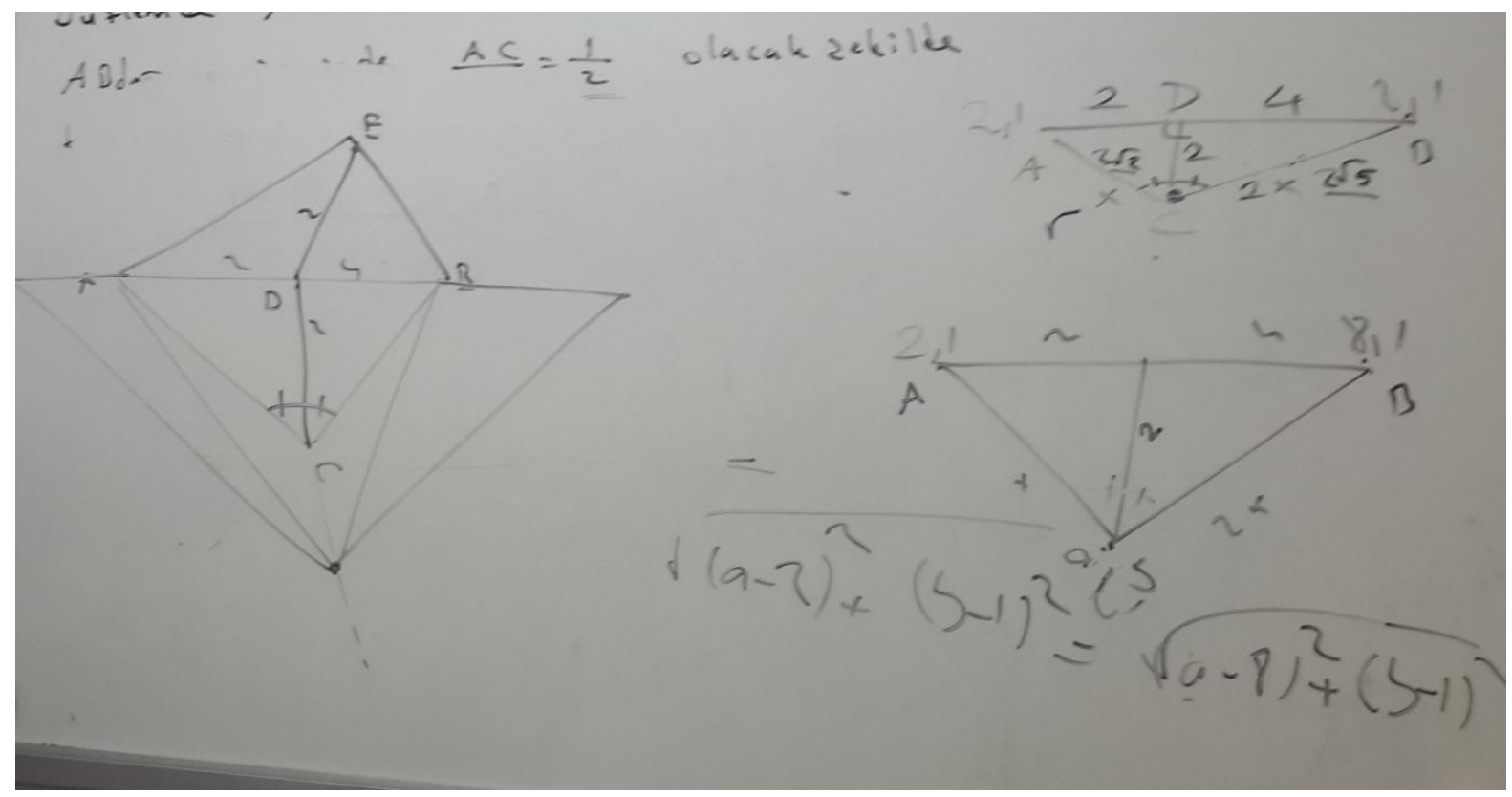

Şekil 2: Istenilen noktanın dışarıda olması durumuna yönelik çalışmalardan bir örnek

Görüldüğü gibi üstün yetenekli bazı öğrenciler, verilen iki noktayı belli bir oranda bölen noktanın doğru dışında olması durumunda bu noktanın açırtay doğrusu üzerinde olabileceğini açıklamaya çalışmışlardır. Bu süreç içerisinde üstün yetenekli öğrencilerden olan Ü2ve Ü3 ile şu şekilde bir diyalog gerçekleşmiştir.

Ü2: Bence burada doğru dışarısındaki nokta C olsa idi. Bu A ve B noktalarına $x$ ve $2 x$ birim uzaklıkta olacaktı. Bu durumda aklıma üçgende açıortay bă̆ıntısı geldi.

A1: Nasil yani?

Ü2: Yani hocam mesela 1/2 oranı olduğundan atıyorum burası 2 birim olsa burasıda 2 burast 4 birim. Şurası dik olsa burası 2 kök 2, burası da 2 kök 5. Ama olmadı o zaman burası dik değil pardon.

Ü3: Orada C noktasinı (a,b) alsak.

Ü2: Evet. Aldım. İki nokta arasındaki uzaklık formülünü yazdiğımızda. 2ICAI = ICBI olacaktır.

İlk başta alınan noktanın yukarıda da görüldüğü gibi açırtay doğrusu üzerinde olabileceğini ifade eden üstün yetenekli öğrenciler bu nokta hakkında tam bir bilgiye ulaşamamışlardır. Ardından noktanın başka yerlerde de olabileceğini ifade eden öğrenciler bu noktayı özel olarak alabileceklerini belirtmişlerdir. Sonuçta özel üçgen oluşturmuşlar ve tek bir noktayı bulduktan sonra üstün yetenekli öğrencilerden biri bu noktanın bir çember üzerinde gezinebileceği tahminini yaparak tahtaya şeklini çizmeye çalışmıştır. 


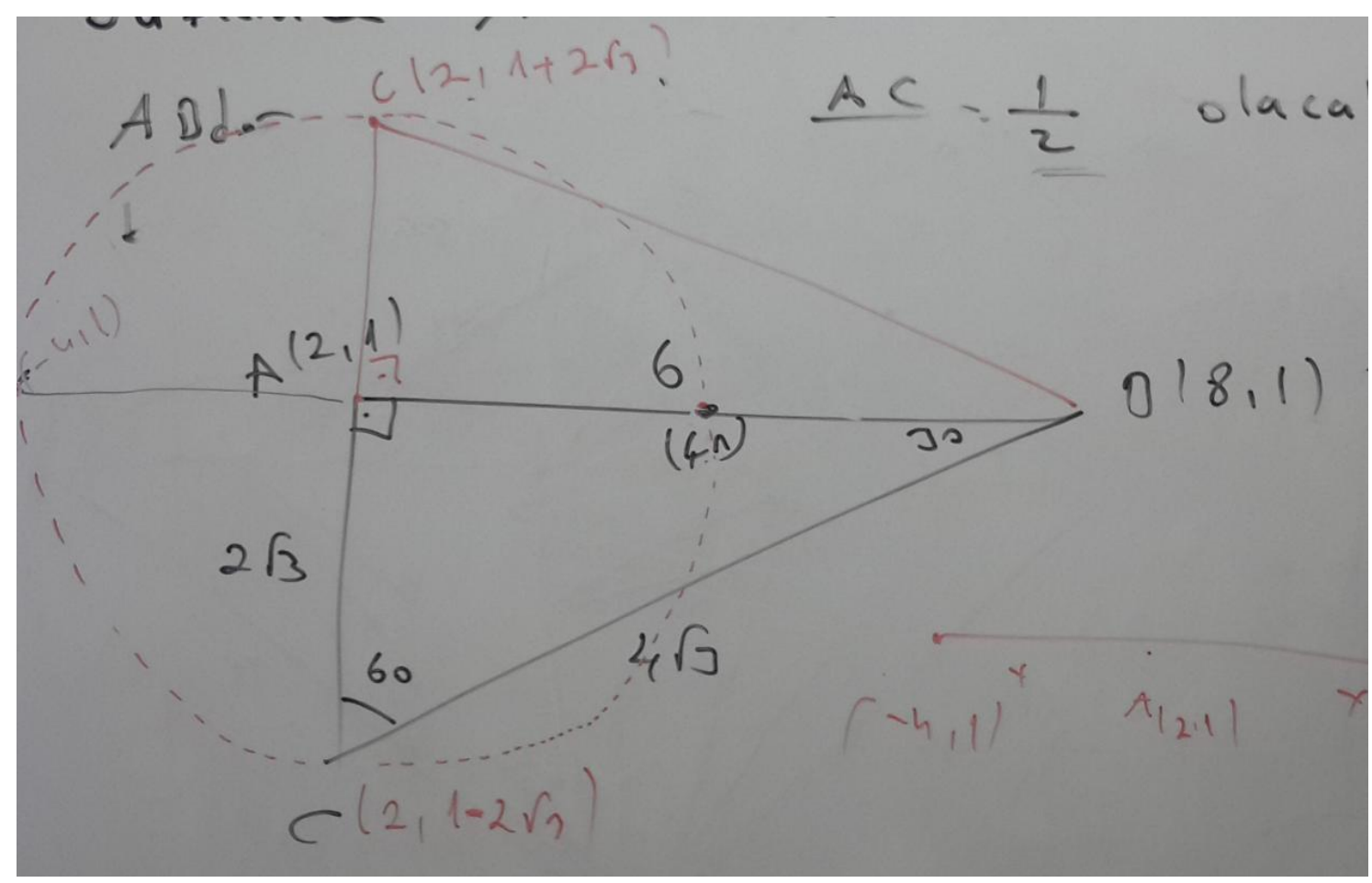

Şekil 3: Ü4 ve Ü6'nın tahminlerini ispat etmelerine yönelik bir kesit

Ü6: $A(2,1)$ ve B(8,1) olduğundan 30-60-90 özel üçgenini oluşturaltm bence. O zaman AC uzunluğu 2 kök 3 birim olur. Bu durumda C ve C' noktaları 1-2kök3 ve 1+2kök3 olacaktır. Ü4: Acaba bu noktalar çember üzerinde geziniyor olabilir mi? Yani şurayı çizdiğimizde bu çember üzerinde gezindiğini gösterebilir miyiz?

Görüldüğü gibi üstün yetenekli öğrenciler, dışarda bulunan noktanın çember üzerinde gezinebileceği tahmininde bulunmuşlardır. Fakat bu tahminlerini kâğıt-kalem ortamında gösterememişlerdir. Ardından öğrenciler bu tahminlerini GeoGebra yazılımında doğrulamaya çalışmışlardır. Fakat öğrenciler sadece yaptıklarının yanlış olduğunu yazılım ekranından gözlemlemelerine rağmen, istenilen noktanın çember üzerinde gezindiği sonucunu ispat edememişlerdir. Bu sürece ait öğrencilerin aralarında geçen örnek bir diyalog ve GeoGebra ekranında oluşturmuş oldukları şekil aşağıdaki gibidir.

Ü3: GeoGebra ekranında düşündüklerimizi bir oluşturalım. Aynı şekilde kâğı̆t-kalem ortamındaki bulduklarımı giriş ekranına yazıyorum.

Ü5: Tamam. Kök komutu sqrt idi ekledim. Evet, şu şekilde bir sonuç. Merkezi A noktası ve C noktasından geçen bir çember çizdim. Kesim noktası olan E noktasının apsisi 6 değil bu olmadı bence.

Ü3: Ama nasıl? Bunu nasll ifade edeceğiz? Yine $(x, y)$ noktası desek uzunluk formülünden az önce yazdlğımızın aynısını yazdık ama. Neyse burası bu şekilde kalsın. Bence tam olarak açıklayamıyorum sadece bir tahmin benimki. 


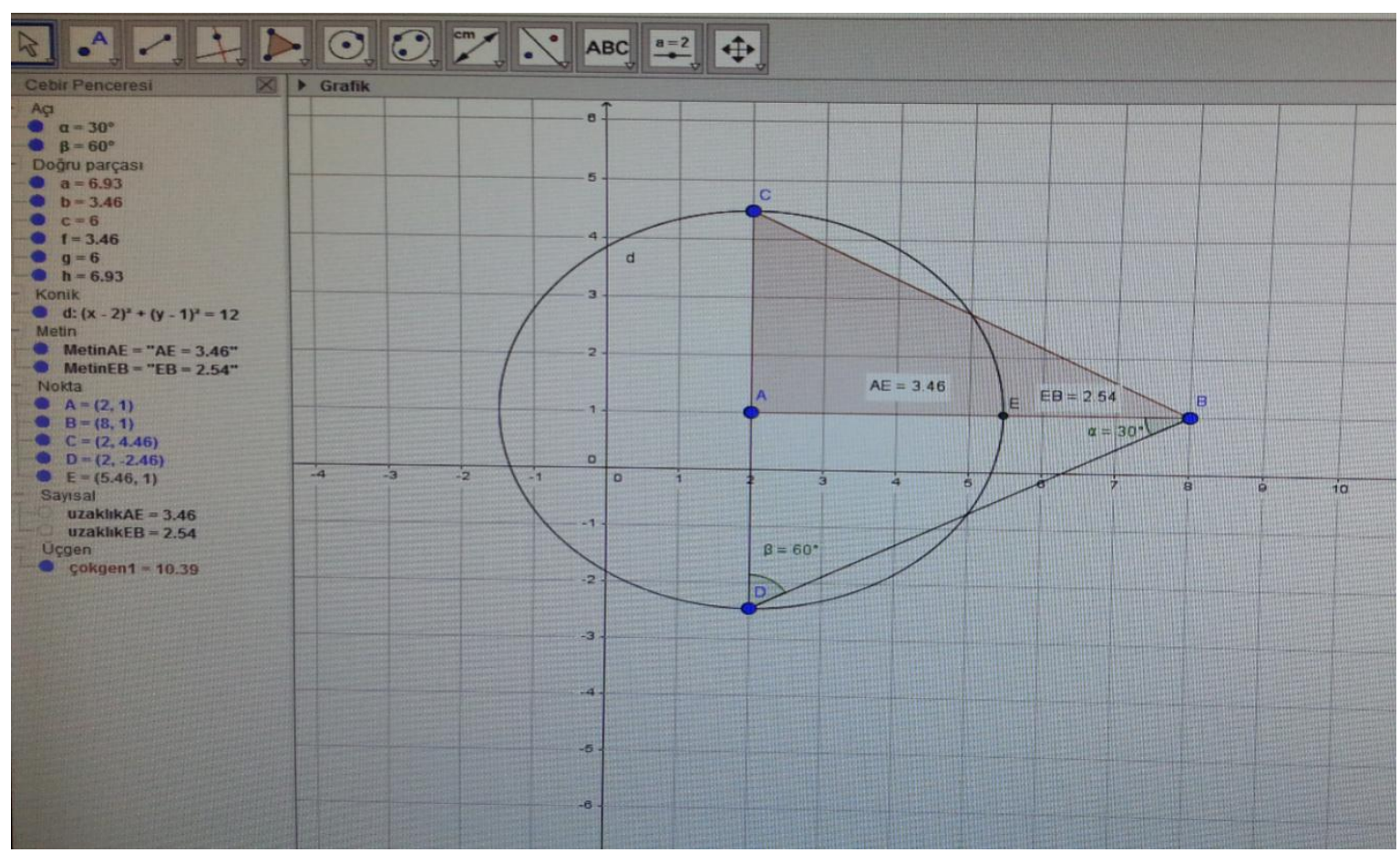

Şekil 4: Ü3 ve Ü5'in tahminlerini yazılım ile ispat etmeye çalışmalarına yönelik bir kesit

Hem GeoGebra ekranında yapılanlar hem de öğrencilerin diyaloglarından görüldüğü gibi tahtada yapılan süreç ekranda kontrol edilmeye çalışılmıştır. Bu süreçte problemde verilen oranın $1 / 2$ olması ve bu orana ait olan noktaların çember üzerinde gezinebileceği fikri AE uzunluğu ve EB uzunluklarının bulunmasıyla çürümüştür. Yani üstün yetenekli öğrenciler GeoGebra ekranında yaptıkları yanlışlık neticesinde istenilen noktanın, merkezi A noktası olan çember üzerinde olamayacağını anlamışlardır. Ardından doğru parçasını bölen noktanın koordinatlarını matematiksel olarak genelleştirmeye çalışan üstün yetenekli öğrenciler aşağıdaki şekilde görüldüğü gibi doğru sonuca ulaşabilmişlerdir.

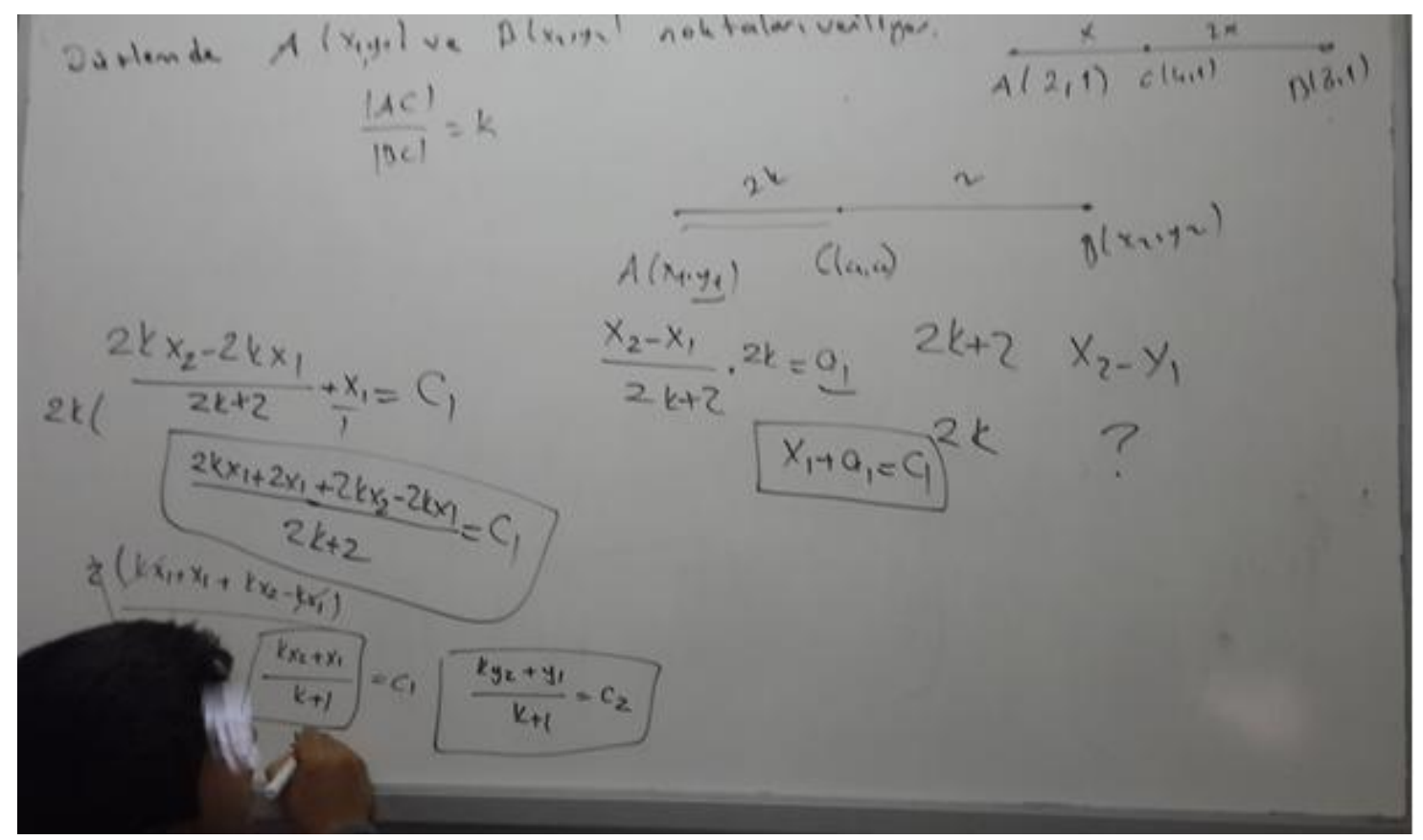

Şekil 5: İlk gruptaki öğrencilerin bir doğru parçasını belli bir oranda bölen noktaları matematiksel olarak genelleştirmeleri 
Ardından üstün yetenekli öğrencilerden köşe koordinatları belli olan bir üçgenin ağırlık merkezinin koordinatlarını belirlemeleri istenmiştir. Bu süreçte üstün yetenekli öğrenciler köşe koordinatlarının üçte birinin ağırlık merkezinin koordinatları olacağını belirtmişlerdir. Bu sürece yönelik öğrencilerin aralarındaki diyalog aşağıdaki gibidir.

\section{Ü1: Burada ă̆ıllı merkezinin koordinatları apsislerin toplamının üçte biri ve ordinatların toplaminın üçte birine eşittir. \\ Ü3: Yani köşse koordinatları $A\left(x_{1}, y_{1}\right) ; B\left(x_{2}, y_{2}\right)$ ve $C\left(x_{3}, y_{3}\right)$ olan üçgenin ă̆ırlık merkezinin koordinatlarl $G\left(\left(x_{1}+x_{2}+x_{3}\right) / 3,\left(y_{1}+y_{2}+y_{3}\right) / 3\right)$ olacaktır. \\ A1: Neden bu şekilde? Sanki ezbere söylediniz gibi. \\ Ü2: Valla benim aklımda hep bu şekilde.}

Yukarıdaki diyaloglardan da görüldüğü gibi üstün yetenekli öğrenciler verilen üçgenin ağırlık merkezini ezbere söyleyebilmektedirler. Bu süreçte öğrenciler, ispat için ne yazılımı ne de kâğıt kalemi kullanma ihtiyacı duymamışlardır.

İkinci gruba ait uygulama süreci ve son revize;

İlk gruba uygulanan etkinliğin zaman alması, öğrencilerin sıkılmaları ve üstün yetenekli öğrencilerin bazı noktalarda sonuca ulaşamamaları nedeni ile etkinlik tekrar revize edilmiştir. Bu şekilde zaman problemi ortadan kaldırılmaya çalışılmış ve etkinlik 4 parçaya bölünmüştür. Ayrıca ikinci grup ile dört ders süresi boyunca kısa aralıklarla bir araya gelinmiştir. Bu sürece ait bulgular ise aşağıdaki gibidir.

İlk grupta olduğu gibi bu gruptaki üstün yetenekli öğrenciler de istenilenleri oluşturarak doğru parçasını içten ve dıştan bölen noktaların koordinatlarını rahatlıkla belirleyebilmişlerdir. Ardından öğrencilere, bu noktanın dışarıda olması durumu sorulduğunda üstün yetenekli öğrencilerden çoğu bir denklem bulmuş fakat bu denklemi yorumlayamamıştır. $\mathrm{Bu}$ sebeple öğrencilerin çoğu bulunan denklemi, GeoGebra ekranında yazmayı istemiştir. Bir müddet sonra ortaya çıkan denklemin çember olduğunu yazılım ekranında gözlemleyen üstün yetenekli öğrenciler, istenilen orana sahip olan dışardaki noktaların bir çember üzerinde olduğunu ifade edebilmişlerdir. Bu sürece ait görüntüler ve bir öğrencinin ifadeleri örnek olarak aşağıdaki gibidir.

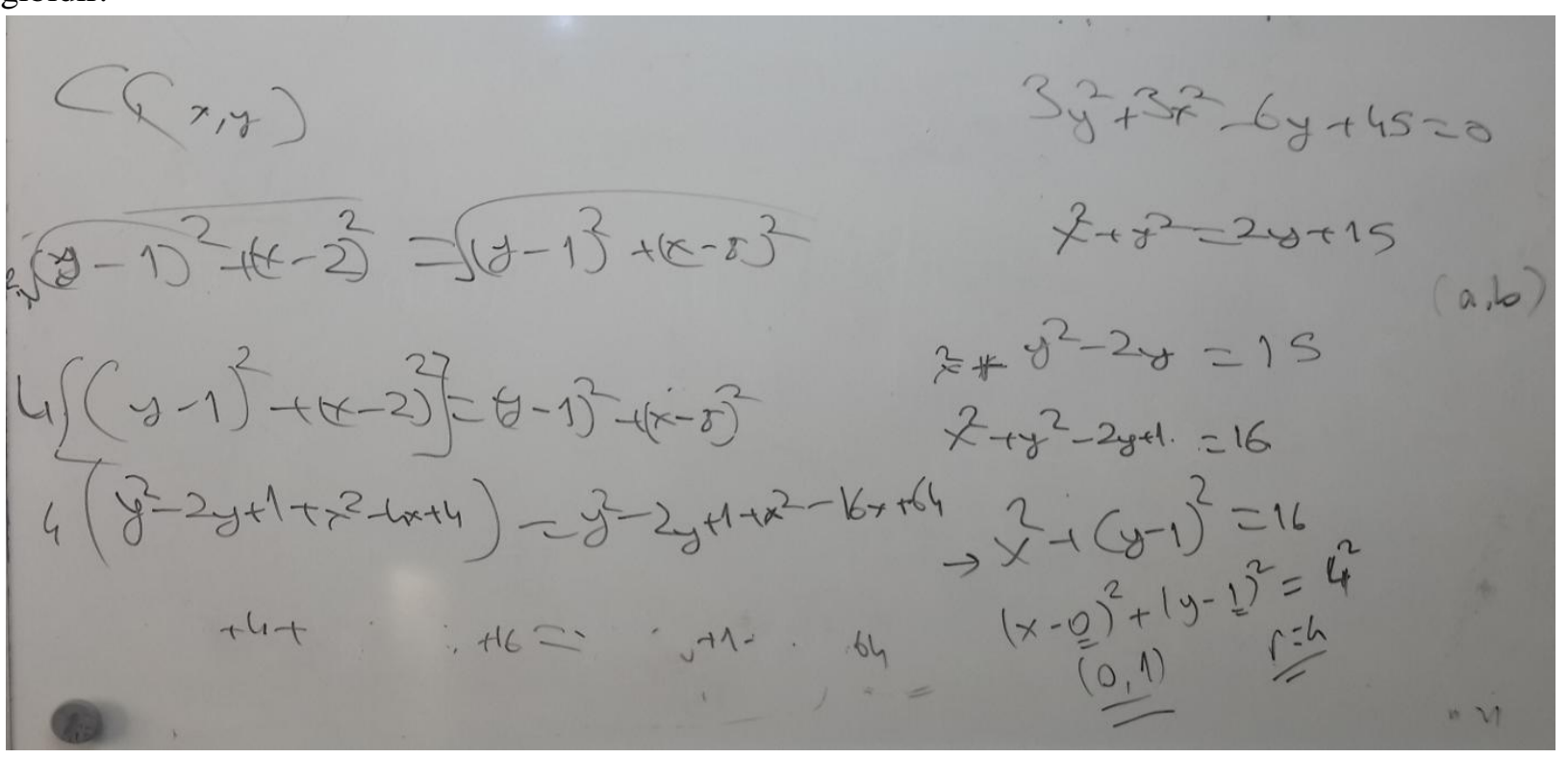

Şekil 6: İkinci grubun istenilen noktanın dışarıda olması durumunda oluşturduğu matematiksel denklem 
Ü10: Herhangi bir $(x, y)$ noktasını aldı̆̆ımızda buradaki uzunluk diğerinin iki katı..

A1: Tamam. Devam edelim. Nasıl gösterebiliriz bunu?

Ü10: Evet buradan hareketle şu şekilde $x^{2}+y^{2}-2 y+1=16$ denklemi çıktı. Bunu bir GeoGebra ekraninda yazabilir miyiz? Aklıma geldi de.

A2: Tabiiki yazabiliriz. Bir dene istersen. Daha güzel gözlemlemiş olursun.

Ü10: Ha. Tamam. Bu bir çember çıktı. O zaman şu noktaları da yerleştireyim. Uzunluklara da bakayım. Evet, istenilen oranların değişmediğini noktayı çember üzerinde gezdirdikçe cebir ekranından görebiliyorum. Bu program güzel ya.

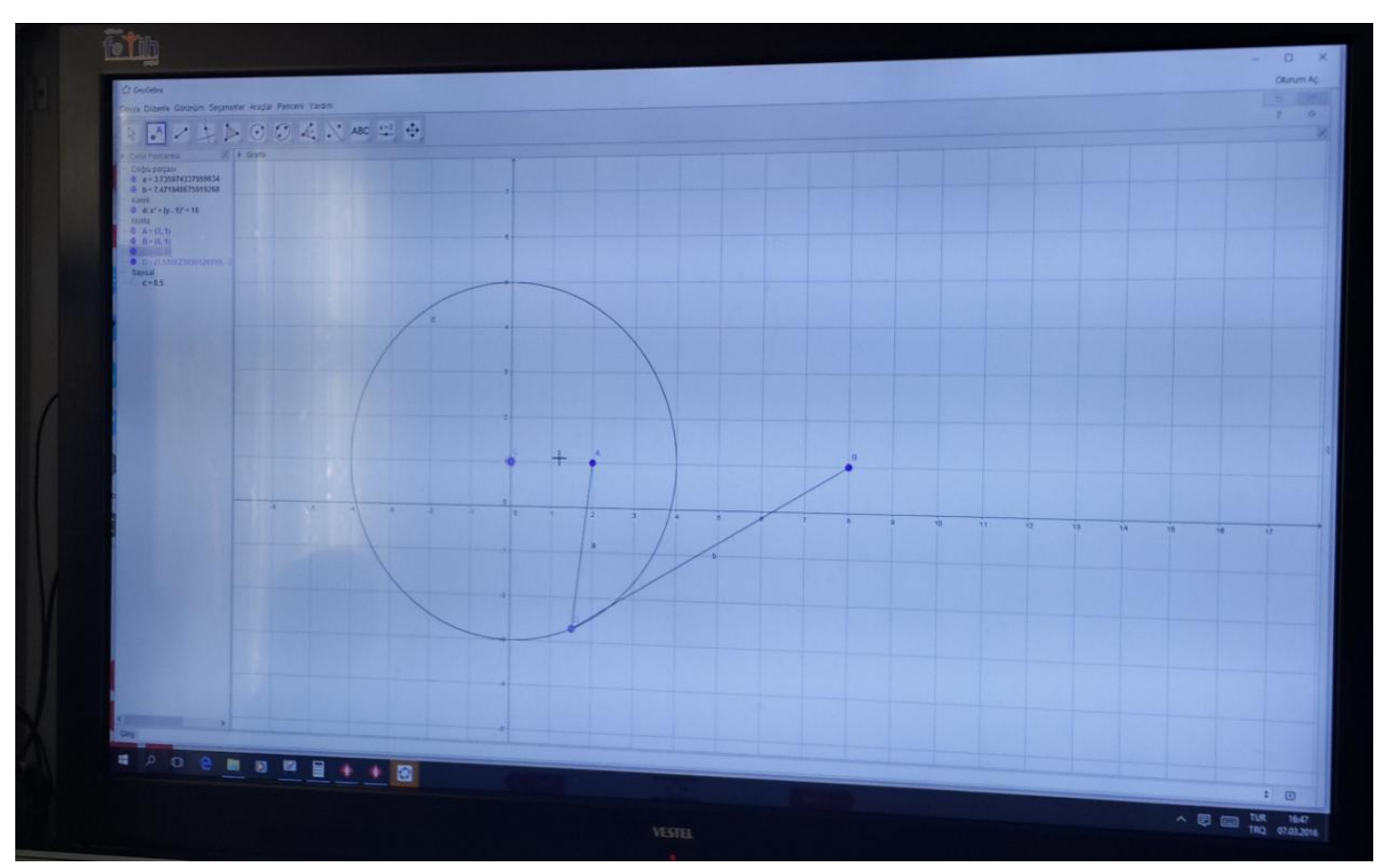

Şekil 7: Ü10’un istenilen noktanın dışarıda olması durumunu yazılımdan gözlemlemeleri

Yukarıda da görüldüğü gibi araştırmacılar, ilk grupta kazandıkları deneyimlerin ardından daha uygun ipuçlarıyla öğrencileri GeoGebra yazılımı ile keşif sürecine yönlendirmişler, bütün öğrenciler de bu keşif süreci ile doğru sonuca ulaşabilmiş̧ir. Ardından öğrencilere köşe koordinatları belli olan bir üçgenin ağırlık merkezinin koordinatları sorulmuştur. İkinci gruptaki öğrencilerde üç noktanın köşe koordinatlarının aritmetik ortalamalarının ağırlı merkezinin koordinatlarını vereceğini belirtmişlerdir. Sonrasında araştırmacının "nasıl ispat edebiliriz?" sorusuna yönelik olarak öğrenciler, geçmiş bilgilerini kullanmaya çalışmışlardır. Bu süreçte öncelikli olarak GeoGebra yazılımını kullanmaya çalışan çoğu üstün yetenekli öğrenci, yazılım ekranında bir üçgen alarak ağırlık merkezinin koordinatlarını cebir ekranından kontrol etmişlerdir. Ardından tahtada istenilenleri aşağıdaki şekilde görüldüğü gibi yapmaya çalışmışlardır. Bu sürece ait ifadeler ve kesitler aşağıdaki gibidir.

Ü9: Üçgenin köşe koordinatları verildiğinde ă̆ırlık merkezinin koordinatları, toplamlarının üçte birine eşittir.

A4: Neden bu şekilde düşündün Ü9?

Ü9: Aklımda hep bu şekilde kalmış hocam. Ama GeoGebra ekranında bir deneyeyim.

A4: Tamam. Bir dene istersen. 
Ü9: Şimdi köşe koordinatlarını aldım. Ăgırlı merkezi kenarortayların kesim noktası idi. $B C$ 'nin orta noktası $E$, aynı şekilde AB'nin orta noktası $F$ ise bunların kesim noktası ağırlık merkezini verir. Zaten uzunluklara baktığımda tabana bir birim iken köşeye iki birim uzaklıkta. Köşe koordinatlarının üçte biri de D noktasını veriyor. Cebir ekranından bunu gözlemliyorum.

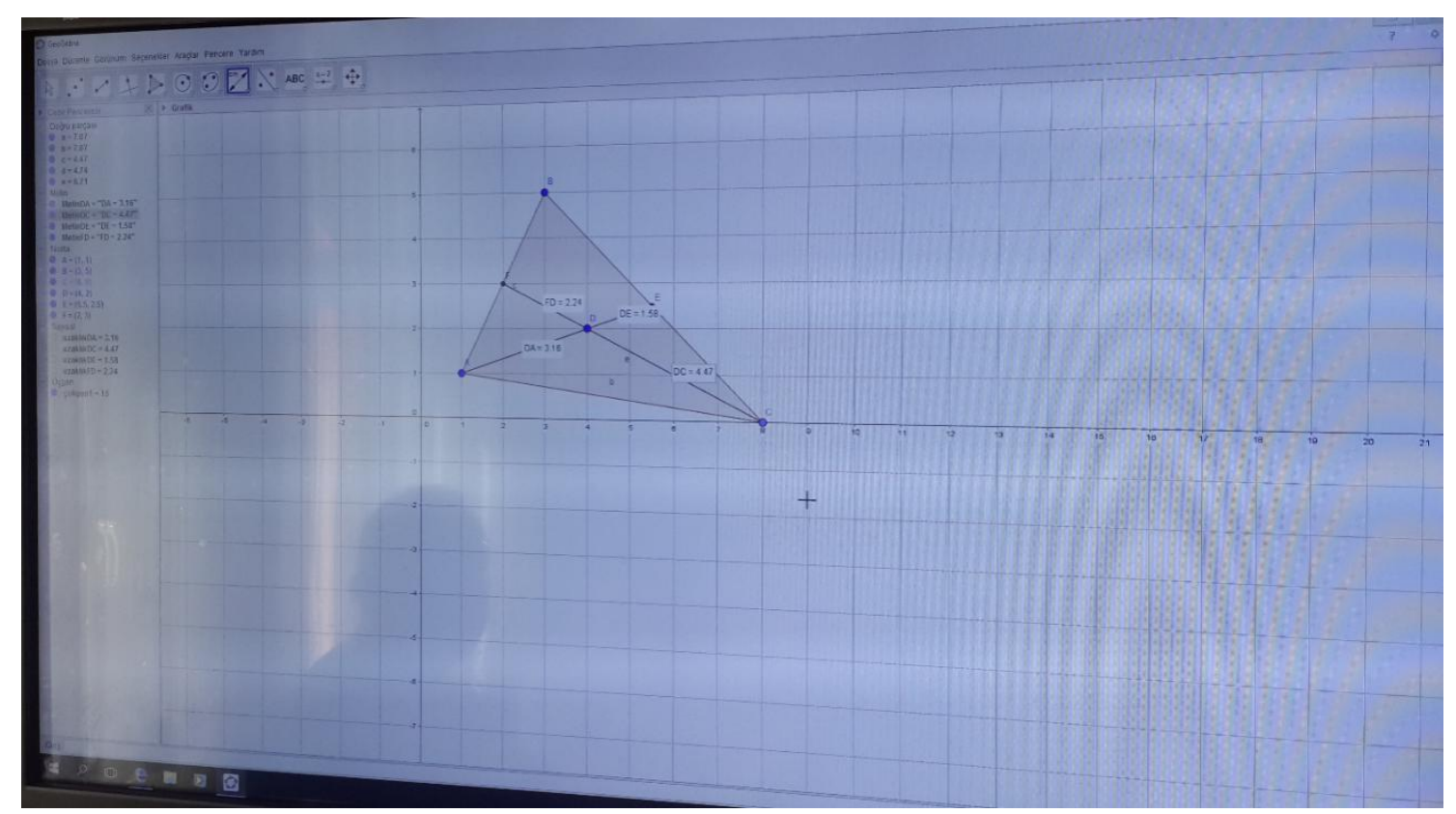

Şekil 8: İkinci grubun köşse koordinatları verilen bir üçgenin ağırlık merkezini yazılım ile keşfetmelerine yönelik bir kesit

A3: Tamam. Köşe koordinatları bu şekilde verilen bir üçgenin ă̆ırlı merkezinin koordinatlarını nasıl genelleştiririz bir bakın bakalım.

Ü7: Bence burada daha önce yaptıklarımızın aynısı. Yani mesela burası orta nokta zaten. Bunu belirlemiştik toplamların yarısı. Belli oranda bulunan formülü de belirledik buradan sonuca ulaşabiliriz. 


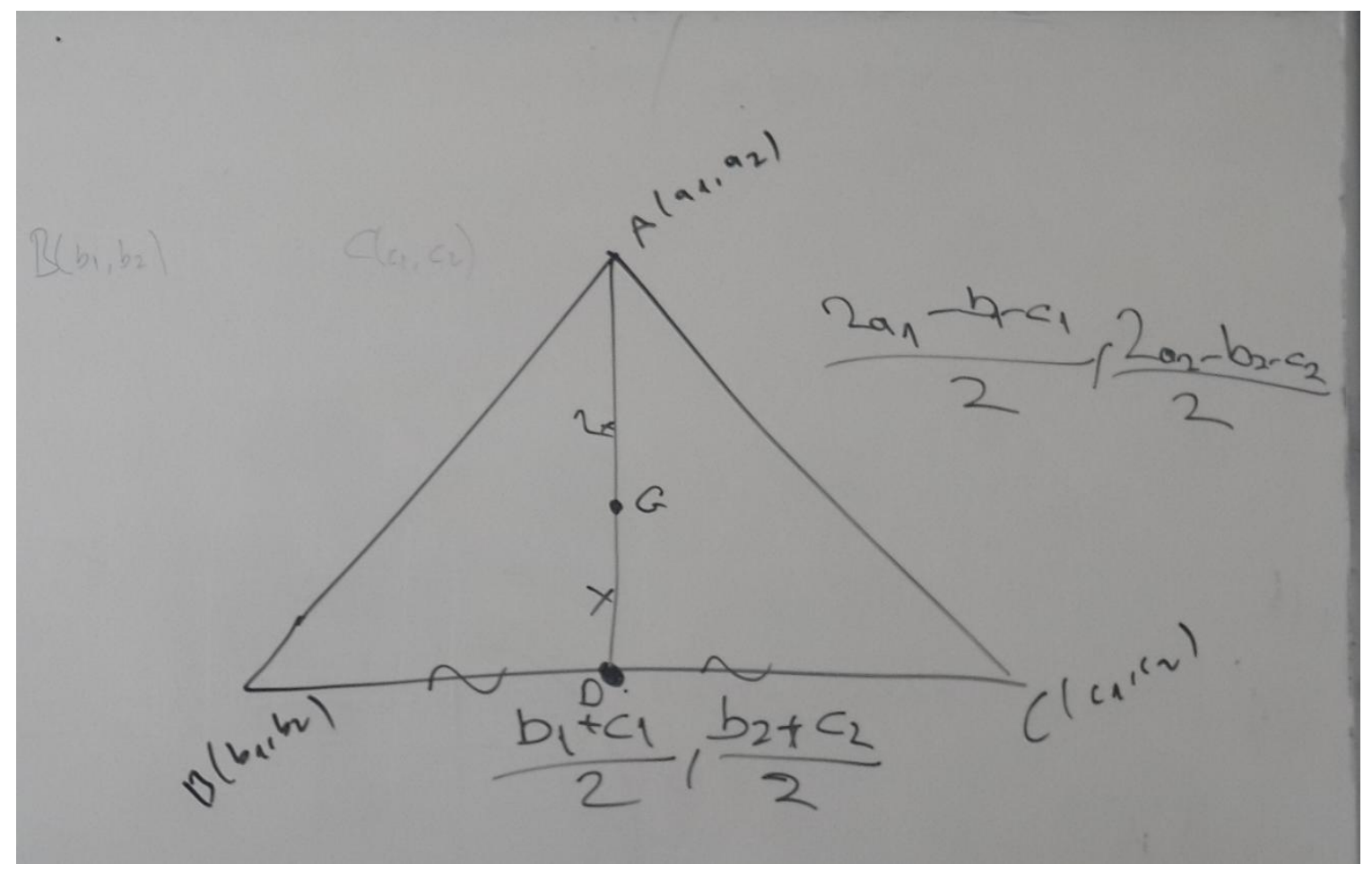

Şekil 9: Köşe koordinatları verilen bir üçgenin ağırlık merkezinin matematiksel genelleştirilmesine yönelik bir kesit

Görüldüğü gibi üstün yetenekli öğrencilerin çoğu ilk gruptaki gibi sonucu hemen söyleyebilmişlerdir. Ardından araştırmacıların yönlendirmeleri ile düşündüklerini GeoGebra'da uygulamaya çalışmışlardır. Sonrasında ise çoğu sonuca ulaşmıştır.

İkinci uygulamanın ardından araştırmacılar ile BİLSEM matematik öğretmenleri bir araya gelerek revize edilen etkinlikte yer alan yönergelerin son halini aşağıdaki gibi belirlenmiştir.

"Herhangi iki $A\left(x_{1}, y_{1}\right)$ ve $B\left(x_{2}, y_{2}\right)$ noktası için $\frac{|A C|}{|B C|}=k$ olduğunda $A B$ doğrusu üzerinde istenilen C noktasını matematiksel olarak genelleştiriniz?"

"Düzlemde herhangi iki A ve B noktaları veriliyor. $\frac{|A C|}{|B C|}=k$ olacak şekilde bir C noktasını nasıl belirlersiniz?"

"Köşe koordinatları $A\left(x_{1}, y_{1}\right), \quad B\left(x_{2}, y_{2}\right) v e \quad C\left(x_{3}, y_{3}\right)$ olan bir üçgenin ăgırlı merkezinin koordinatlarını belirleyiniz?"

\section{Tartışma ve Sonuç}

Yapılan bu çalışmada, üstün yetenekli öğrencilere yönelik GeoGebra yazılımının da süreçte etkili olduğu etkinlikler hazırlamak için tasarım tabanlı araştırma sürecinin yansıtılması amaçlanmıştır. Araştırma sonuçlarına göre üstün yetenekli öğrencilere etkinlik hazırlamanın kolay bir süreç olmadığı ve bu etkinliklerin BİLSEM matematik öğretmenlerinin görüşleri de alınarak geliştirilmesinin yararlı olduğu belirlenmiştir. Edelson (2001) da tasarım tabanlı araştırma yönteminin hem bir tasarımın geliştirilmesini sağladığını, hem de süreç içindeki araştırmacıların olayları daha iyi anlamasına yol açtığını ifade etmektedir. Diğer taraftan araştırmada, üstün yetenekli öğrencilere yönelik hazırlanan etkinliklerin üzerinde her öğrencinin fikir beyan edebileceği, merak uyandıran, keşfettiren, rutin problemlere benzemeyen ve sınıf içerisindeki işbirliğine uygunluk hususlarına sahip olması gerektiği sonucuna ulaşılmıştır. Bu sonuçların 
Smutny, Walker ve Meckstroth (1997), Reece ve Walker (1997) ve Baki (2008) tarafından yapılan önerilere uygun olduğu anlaşılmaktadır. Belirtilen önerilere göre hazırlanan etkinlikler sayesinde üstün yetenekli öğrencilerin yaratıcı fikirleri de ortaya çıkarılabilir. Gerek BİLSEM gerek diğer okullarda bu şartlar ile etkinlikler oluşturularak öğrenme ortamları dizayn edilirse üstün yetenekli öğrencilerin gereksinimlerine uygun yetiştirilmesi sağlanabilir.

Öğretmen görüşleri alınsa bile bir gruba uygulama yapıldıktan sonra bazı düzeltmeler yapılmasının gerekliliğinin ortaya çıkması, bu gruba uygun etkinlik tasarlama işinin oldukça zor olduğunu göstermektedir. Bu bağlamda Collins (1992), tasarım deneyleri ile birlikte sosyal etkileşimin çok önemli bir rol oynayacağını belirterek işbirliği sürecine vurgu yapmıştır. Ayrıca tasarım tabanlı araştırma yönteminin, ilk grup öğrencilerden elde edilen verilere göre öğretmen ve araştırmacılara yeni bakış açıları kazandırdığı sonucuna ulaşılmıştır.Kelly (2003) de tasarım tabanlı araştırmalarla araştırmacıların bütün süreçte aktif olduğunu belirtmiştir. Ayrıca Wang ve Hannafin (2005) bu sayede araştırmacıların katılımcılar ile işbirliği içerisinde çalıştığını ifade ederek araştırmacıların deneyim kazandıklarını vurgulamıştır. Bu çalışmada olduğu gibi yapılacak olan araştırmalarda araştırmacılar yapacakları çalışmaları öğrenciler ve onların öğretmenleri ile birlikte yapması sonucunda çeşitli deneyimler kazanabilirler.

Araştırmada tasarım tabanlı çalışmalar ile BİLSEM öğretmenlerinin teknoloji kullanma isteklerinin daha da arttığ 1 , bunun için öğretimlerini GeoGebra yazılımı ile şekillendirmeleri gerektiğini ifade etmişlerdir. Aslında bu durum, üstün yetenekli öğrencilerin gereksinimlerine cevap verebilmek için bu araştırmaya katılan üç BİLSEM matematik öğretmenine dinamik yazılımlara yer vermenin sağladığı olanakları, tasarım tabanlı araştırma çalışmaları ile göstermenin onlarda olumlu bir düşünceye yol açması bakımından sevindirici bir durumdur. Benzer şekilde bu kurumlarda çalışan öğretmenlere, gerek hizmetiçi kurslarla gerekse de araştırmada kullanıldığ gibi akademisyenler ile eğitimcilerin biraraya gelerek çalışmalarına izin veren bu tarz yaklaşımlarla dinamik yazılımları kullanma ve derslerine uygun bir şekilde entegre etme becerisi verilebilir.Bu önerilere benzer şekilde Baki, Yıldız ve Baltacı (2012) ve Aydos (2015) yapmış oldukları çalışmalarında GeoGebra dinamik yazılımının üstün yetenekli öğrencilerin eğitiminde kullanılmasının önemli olduğunu ve bu şekilde etkili bir öğretimin gerçekleşebileceğini ortaya koymuşlardır.

Her iki grupta da bütün üstün yetenekli öğrenciler istenilenleri oluşturarak doğru parçasını içten ve diştan bölen noktaların koordinatlarını rahatlıkla belirleyebilmişlerdir. Yapılan çalışmalar üstün yetenekli öğrencilerin problemlere farklı çözümler getirmede istekli olduklarını göstermektedir (Aydos, 2015; Baltacı, Yıldız \& Güven, 2014; El-Demerdash, 2010). Araştırmada öğrencilerdeki bu isteği artırmak için bütün süreçte araştırmacılar ve BILLSEM matematik öğretmenleri görüş alış verişinde bulunmuşlardır. Diğer taraftan ilk gruptaki öğrencilere, bu noktanın dışarda olması durumu sorulduğunda üstün yetenekli öğrencilerden çoğu çember tahmininde bulunmuş fakat bu tahminlerini hem kağıt kalem ortamında hem de yazılımla ispat edememişlerdir. Ardından araştırmacıların kazandığı deneyimlerle bu durum, başarı bakımından benzer olan ikinci grup için söz konusu olmamıştır. Benzer durum köşe koordinatları belli olan bir üçgenin ağırlık merkezinin koordinatlarını bulma konusunda da olmuştur. İlk grup ezbere birşeyler ifade etmeye çalışırken ikinci grup GeoGebra yazılımı ile keşif sürecine girmiş ve başarılı olmuştur. Olive (2002) de öğrencilerin dinamik yazılımlar sayesinde; matematiği hesaplama ve sembolik ifadelerle soyut olarak algılamak yerine, bir bilim adamı gibi kendisi araştıran, matematiği bir oyun gibi görerek yaptıklarından zevk duyan, öğrenme rolünün büyük bir kısmının kendinde olduğunun farkında olan bir öğrenme gerçekleştirebileceğini ifade etmiştir. Ayrıca Kokol-Voljc (2007), Gürsoy, Yıldız, Çekmez ve Güven (2009) ve Yıldız, Güven ve Koparan (2010) dinamik geometri yazılımlarının geometri öğretimine yeni bir boyut kazandırdığını belirtmektedir. Yapılan bu çalışmada da özellikle ikinci gruptaki üstün yetenekli öğrencilerin istenilen noktanın dışarıda olması durumunda noktanın çember üzerinde gezindiğini gözlemlemeleri ve üçgenin ağırlık merkezinin koordinatlarını keşfedebilmeleri onların yazılıma karşı daha çok istekli olmalarını 
sağlamıştır. Bu durum, dersler planlanırken dikkate alınırsa bütün öğrencilerin matematik derslerine karşı istek ve tutumları olumlu yönde değiştirilebilir.

Araştırmada BİLSEM matematik öğretmenlerinin; Bilim ve Sanat Merkezine alınan üstün yetenekli öğrencilerin eğitimlerinde ders saatlerinin başlama saatleri ve onlarla ilgilenme süreleri gibi olumsuz durumların teknoloji kullanım becerilerini etkilediğini ve bu yüzden bazı değişikliklerin olması gerektiğini vurguladıkları belirlenmiştir. Bunun için Bilim ve Sanat Merkezlerinin ayrı bir okul olması, öğrencilerin ve BİLSEM öğretmenlerinin okula ayıracağı bütün zamanlarını bu merkezlerde geçirmesi bu tür zorlukların önüne geçmesinde fayda sağlayabilir. Ayrıca araştırmanın sonuçlarına yönelik olarak üstün yetenekli öğrencilerin gereksinimlerine uygun etkinlikler tasarlamak isteyen eğitimciler, tasarım tabanlı araştırma yönteminin potansiyellerinden yararlanabilirler. Diğer taraftan bir etkinliğin üstün yeteneklilere uygun olmasının yanında, uygulayıcıların üstün yetenekli öğrencilere bir etkinliği nasıl sunabileceklerine ilişkin verilerin de böyle bir süreç içinde ortaya çıkabileceği unutulmamalıdır.

\section{Kaynakça}

Akarsu, F. (2001). Üstün yetenekli çocuklar. Ankara: Eduser Yayınları.

Aktümen, M., Horzum, T., Yıldız, A. \&Ceylan T. (2010). Bir dinamik matematik yazılımı: GeoGebra ve ilköğretim 6-8. sınıf matematik dersleri için örnek etkinlikler, ISBN: 978-605-125-189-9. http://ankarageogebra.org/cms/aktumen/ekitap/ adresinden 15.04.2016 tarihinde alınmıştır.

Aydos, M. (2015). The impact of teaching mathematics with GeoGebra on the conceptual understanding of limits and continuty: The case of Turkish gifted and talended students. Published Master of Thesis, Bilkent University, Ankara, Turkey.

Baki, A. (2008). Kuramdan uygulamaya matematik eğitimi. Ankara: Harf Eğitim Yayınları.

Baki, A., Yıldız, A. \&Baltac1, S.(2012). Mathematical thinking skills shown by gifted students while solving problems in a computer-aided environment. Energy Education Science and Technology Part B: Social and Educational Studies, Special Issue, 993-995.

Baltacı, S. (2014). Dinamik matematik yazılımının geometrik yer kavramının ögretiminde kullanılmasının bağlamsal ögrenme boyutundan incelenmesi (Yayınlanmamış doktora tezi). Karadeniz Teknik Üniversitesi, Trabzon, Türkiye.

Baltacı, S., Yıldız. A. \&Güven, B. (2014). Knowledge types used by eighth grade gifted students while solving problems. Bolema, 28 (50), 1032-1055.

Brown, A.L. (1992). Design experiments: Theoretical and methodological challenges in creating complex interventions in classroom settings. Journal of the Learning Sciences, 2 (2), 141-178.

Collins, A. (1992). Towards a design science of education. In E. Scanlon ve T. O'Shea (Eds.), New directions in educational technology (pp. 15-22). Berlin: Springer.

Collins, A., Joseph, D. \& Bielaczyc, K. (2004). Design research: Theoretical and methodological issues. Journal of the Learning Sciences, 13 (1), 15-42.

Creswell, J. W. (2005). Educational research: planning, condacting, and evaluating quantitative and qualitative research (2th ed.). New Jersey, Pearson Education, Inc, Upper Saddle River. 
Design-Based Research Collective (2003). Design based research: An emerging paradigm for educational inquiry. Educational Researcher,32 (1), 5-8.

Doğan, Y. \& Gürel, Z. (2013). Kamp ateşi yakma deneyimi bağlamında difuzyon kavramının gelişiminin incelenmesi. 1.Ulusal Fizik Eğitimi Kongresi. Hacettepe Üniversitesi. 12-14 Eylül, Ankara, Türkiye.

Edelson, D.C. (2001). Design research: What we learn when we engage in design. Journal of the Learning Sciences, 11 (1), 105-121.

Edwards, J. A. \& Jones, K. (2006). Linking geometry and algebra with GeoGebra. Mathematics Teaching, 194, 28-30.

El-Demerdash, M. (2010). The effectiveness of an enrichment program using dynamic geometry software in developing mathematically gifted students' geometric creativity in high schools (Doctoral dissertation). University of Education Schwäbisch Gmünd, Germany.

Gürsoy, K., Yıldız, C., Çekmez, E., \& Güven, B. (2009, 7-9 October). The effect of cabri $3 d$ software to the perception errors occuring with depiction of three dimensional geometric figures to two dimensional plane. $3^{\text {rd }}$ International Computer \& Instructional Technologies Symposium, Karadeniz Technical University, Trabzon.

Johnson, B. \& Christensen, L. (2004). Educational research: Quantitative, qualitative, and mixed approaches (2nd Ed.). Boston: Pearson Education, Inc.

Kelly, A.E. (2003). The role of design in educational research. Educational Researcher, 32 (1).

Kertil, M., Erbaş, A. K. \&Çetinkaya, B. (2014). Öğretmen adaylarının iki niceliğin eş zamanlı değişimini içeren durumları modellerken grafik oluşturma ve yorumlama süreçlerinin incelenmesi. Ulusal Fen ve Matematik Eğitimi Kongresi(UFBMEK-XI). Adana, Türkiye.

Kokol-Voljc, V. (2007). Use of mathematical software in pre-service teacher training: Thecase of DGS. Proceedings of the British Society for Research into Learning Mathematics, 27(3), 55-60.

Kuzu, A., Çankaya, S. \& Mısırlı, Z.A. (2011). Tasarım tabanlı araştırma ve öğrenme ortamlarının tasarımı ve geliştirilmesinde kullanımı. Anadolu Journal of Educational Sciences International, 1(1), 19-35.

Kuzu, A., Cavkaytar, A., Çankaya, S. \& Öncül, N. (2013). Zihin engelli bireylerin ebeveynlerinin kullanımına yönelik geliştirilen mobil beceri öğretimi yazılımına yönelik katılımcı görüşleri. Anadolu Journal of Educational Sciences International, 3(2), 1-21.

MEB, (2007). MEB Bilim ve Sanat Merkezi Yönergesi. 25.01.2007 tarih ve 4 sayılı Talim ve Terbiye Kurulu Kararı, Madde 6.

Miller, R.C. (1990). Discovering mathematical talent. (ERIC Digest No. E482) ERIC Clearinghouse on Handicapped and Gifted Children Reston VA.

Olive, J. (2002). Implications of using dynamic geometry technology for teaching andlearning. In: M. Saraiva, J. Matos, I. Coelho (Eds.) Ensino e aprendizagem de geometria (pp. 300-321). Lisbon: SPCE.

Reece, I. \& Walker, S. (1997). Teaching, training and learning: A practical guide. Sunderland: Business Education Publishers.

Sowell, E. J.,Zeigler, A. J., Bergwell, L. \& Cartwright, R. M. (1990). Identification and description of mathematically gifted students: A review of empirical research. Gifted Child Quarterly, 34, 147-154. 
Smutny, J.F., Walker, S.Y. \& Meckstroth, E.A. (1997). Teaching young gifted children in the regular classroom: Identifying, nurturing, and challenging ages 4-9. Minneapolis, MN: Free Spirit.

Yıldırım, G. (2014). Tablet bilgisayarlara yönelik gelişstirilen e-kitapların video ile zenginleştirilmesi süreci: bir tasarım tabanlı araştırma (Yayınlanmamış Doktora Tezi). Atatürk Üniversitesi, Erzurum, Türkiye.

Yıldırım, A. ve Şimşek, H. (2008). Sosyal bilimlerde nitel araştırma yöntemleri (6. baskı). Ankara. Seçkin Yayınc1lık.

Yıldı, A., Baltacı, S., Kurak, Y. \& Güven, B. (2012). Üstün yetenekli ve üstün yetenekli olmayan 8. Sınıf öğrencilerinin problem çözme stratejilerini kullanma durumlarının incelenmesi. Uludă̆ Üniversitesi Ĕ̈itim Fakültesi Dergisi, 25(1), 123-143.

Yıldız, C., Güven, B., \& Koparan, T. (2010). Use of Cabri 2d software in drawing height,perpendicular bisector and diagonal. Procedia-Social and Behavioral Sciences, 2, 2040-2045.

Wang, F. \& Hannafin, M.J. (2005). Design-based research and technology-enhanced learning environments. EducationalTechnology and Development, 53 (4), 5-23.

Wieczerkowski, W., Cropley, A. J. \& Prado, T. M. (2000). Nurturing talents/gifts in mathematics. In K. A. Heller, F. J. Monks, R. J. Sternberg, \& R. F. Subotnik (Eds.), International handbook of giftedness and talent education,(pp. 413-425). Oxford, United Kingdom: Pergamon

\section{Extended Abstract}

\section{Purpose}

Gifted students are the individuals differentiated from others in terms of distribution, frequency, timing and composition of the properties existing in each individual. In line with the research, gifted students in mathematics courses are defined as the individuals revealing their creativity in problem solving process. Gifted students may need various tools in learning environment. In this regard, one of the tools can be used is may be GeoGebra software. In line with these ideas, in this research, design experiment was used to enter into the process of exploration through GeoGebra Software when they need it in paper pencil environment while activities were being developed appropriate for the needs of gifted students.

Design experiment is a new approach based on overhoaling again the instruction strategies and used tools starting from the theory based on the findings obtained from the real application process. The most important feature of the design experiment studies is to be used in an innovation production. This innovation can be a new theory, a new learning environment or a new education application. The number of publication including this method remarkably few because of difficulties in application of the design based experiment and not being enough known by the education researchers.

A few studies were conducted on the issue of design experiment in Turkey when the studies were reviewed. Also, it is obvious that gifted students have different skills compared to their coevals and it is not easy to prepare activities appropriate for these skills. In this regard, it may be said that it is not easy to prepare activities in which the GeoGebra Software can be used appropriate for their need. For this reason, the purpose of the study reflects the process of design experiment method conducted with BILSEM mathematics teachers in order to prepare activities for gifted students. This purpose of the study will be reflected for just one activity because of the long process. Therefore, an opportunity will be created fort he formation of activities responding the needs of gifted students by revealing the process of developing and applying the 
prepared activities with BILSEM mathematics teachers giving courses to gifted students participating the study.

Method

The sample of the research in which the case study method was used consists of 3 BILLSEM mathematics teachers and 12 gifted students as two groups each involving 6 gifted students. The participants were selected in line with the BILLEM teachers' ideas based on the students' skills of using GeoGebra and selecting students having different achievement levels (high, middle, low). On the other hand, one of the teachers have been working as a teacher for 8 years and the other two have been working as teachers for 5 years at the Science and Art Centre. Video records, interviews conducted with students during this process, solutions on the blackboard produced by the students, models that students created on the GeoGebra screen and the statements of BILSEM teachers and the researchers related to the activity creation process were used as the data of the research.

The researchers examined the studies conducted with gifted students before implementing the study. Also, the researchers decided to designe activities in which GeoGebra software can be used. The activities prepared by the BILLSEM teachers and the researchers applied to the first group then applied to the second group after the necessary revisions. The data were analyzed through the content analysis-one of the qualitative analysis methods. The data gathered from the interviews was enumerated and controlled before the data obtained from the research was analyzed. The interviews were transcribed as they were heared without making any correction and paying attention on the interviewer-interviwee order.

Results

Reflections from the activity creation process and the first revision;

In the meetings with BILSEM teachers, it was indicated the importance of paing attention to each student can state her/his idea, to be intriguing, exploring, different from routine problems and appropriate for the inclass collaboration. Then, the activities created by the researchers were discussed with the BILLSEM teachers and an activity was tried to be identified. In this process, BILSEM teachers indicated their opinions on whether the prepared activities were appropriate fort he gifted students attending 10th grade or not. In line with the ideas the activity was finalized as follows.

" The points of $A(2,1)$ and $B(8,1)$ were given in plane. How do you identify point Con the line $A B$ by considering $\frac{|A C|}{|B C|}=\frac{1}{2}$ ? ”

After conducting these meetings, the activity was designed by the researchers again. The following directions were added to the activity.

"Please generalize point $C$ on the line $A B$ when $\frac{|A C|}{|B C|}=k$ for any $A\left(x_{1}, y_{1}\right)$ and $B\left(x_{2}, y_{2}\right)$ points."

"Please identify the center of gravity of the triangle whose corner coordinates are $A\left(x_{1}, y_{1}\right)$, $B\left(x_{2}, y_{2}\right)$ and $C\left(x_{3}, y_{3}\right)$."

Then, the activity organized by the researchers was reviewed again with the BILSEM teachers. In this process, BILSEM mathematics teachers indicated their opinions on the possible changes about the directions on the activities. In line with these opinions, the following question was added to the activity. 
"Any two A and B points were given on plane. How do you identify point $C$ as $\frac{|A C|}{|B C|}=k ?$ ?"

On the other hand, BILLSEM teachers stated that their eagerness of the use of technology increased and they stated that they need to form their instruction with GeoGebra software. Also, BILLSEM mathematics teachers emphasized the need of changes should be done on the course schedule in terms of the starting time and the time needed to spend with each student. Because these issues affect the gifted students' skills of technology use.

Application process of the first group of gifted students and the second revision;

The activity revised after the study of BILSEM mathematics teachers and the researchers was applied to the first group. During the application, the students were required to find the point dividing a given line segment. The gifted students easily did the required activity and they explain it on the board. Then, the question of "Where can be the required point other than this?" was asked to the gifted students. In response, it was observed that some of the students tried to relate with angle bisector of the triangle. The students stating that the point may be in other places indicated that they can take this point separately. As a result, they created a special triangle and after finding only one point one of the gifted students estimated and tried to demonstrate that this point paced on a circle. Then, the students tried to correct their estimations on GeoGebra software. However, the students were able to see the their faults on the software screen, but they were not able to prove that the required point paces on the circle.

Application process of the second group of gifted students and the last revision;

The activity was revised again because the activity applied to the first group took time, the students got bored and the students were not able to reach the right solution for some points. In this way, the time concern was tried to be solved and the activity was divided 4 parts. Also, the researchers got together with the second group for 4 lesson time with small time periods. The gifted students in this group also were able to identify the coordinates of the points dividing the line segments both inside and outside by forming the required directions as happened to the first group. Then, most of the gifted students were able to find an equation when the point is outside but they could not construe the equation. Thus, most of the students tended to write the equation on the GeoGebra screen. The gifted students observed the revealed equation was a circle on the software screen were able to state that the points having the required ratio on outside were on the circle. Then, the researchers got together with the BILSEM teachers and they identified the last version of the directions on the revised activity as follows .

"Please generalize the required point $C$ mathematically on the line $A B$ when $\frac{|A C|}{|B C|}=k$ for any two points $A\left(x_{1}, y_{1}\right)$ and $B\left(x_{2}, y_{2}\right)$."

"Any two points $A$ and B were given. How do you identify the point $C$ as $\frac{|A C|}{|B C|}=k$ ?"

"Please identify the coordinates of the center of gravity of a triangle whose corner coordinates are $A\left(x_{1}, y_{1}\right), B\left(x_{2}, y_{2}\right)$ and $C\left(x_{3}, y_{3}\right)$."

\section{Conclusion and Discussion}

According to the results of this study, it is not an easy process to prepare activities for gifted students and it is very useful to take opinions from mathematics teachers of gifted students in the development process. On the other hand, it has been reached that the activities prepared for the gifted students must have some features such as;each student can be able to declare their own ideas, intriguing, students can be able to learn by exploring relations, unlike the routine problems and activities must be appropriate for cooperation in the 
classroom. Through activities prepared in accordance with these recommendations reveal the creative ideas of gifted students. If the activities were developed by these conditions and used in both gifted students' and other schools, it would procurable to train students according to students' needs. In the development process, there were some requirements to make corrections after the application of these activities which were prepared according to their teachers' views. This shows it is very difficult to develop activities for gifted students. Some previous studies support this finding.

In this research, the teachers involved in the developing process stated that their readiness to use of technology was increased with this design based experiment. Besides, they also stated that they should carry out their teaching with GeoGebra. In fact, despite these teachers involved in this study in order to help researchers and give their recommendation to acitivity developing process for the gifted students, they realized using dynamic give much oppurtunity for effective teaching. This is very plasing to evolve their opinion about effectiveness of using dynamic software. Similarly, it can be given to the teachers, working in the institutions for gifted students, the ability of using dymamic software and integrating this softwares appropriately their course within the in-service training like this research process in which educators and academics work together to produse proper activity for gifted students.

All gifted students in both groups were able to easily determine the coordinates of the internal and external dividing points of a line segment by creating required things on GeoGebra. The studies reveal that gifted students are willing to create different solutions to the problems. In the research process, researchers and teachers shared their views with each other in order to increase the willing level of gifted students. On the other hand, when it was asked to the students in the first group about the stuation of being outside from the line, most of the gifted studens estimated the the geometric locus is a circle but they did not prove this with paper and pencil environment. Then with the experience gained by the researchers of this case, the second group, which is similar to the first grouup in terms of success, has been proved this with paper and pencil after estimating the geometric locus is an circle. A similar situation was also happened about finding the corner coordinates and the coordinates of the center of gravity of a certain triangle. When, the first group was trying to express something by memorization, the second group has been entered a process of discovery and has been successful. In this study, especially the gifted students in the second group has been more willing to the software because that they observed interactively the desired point which is outside of the line while moving on a circle and they explored gravity coordinates of a triangle's center. If this situation is taken into account when planning the course, all students' willings and attitudes towards mathematics would be changed in a positive way.

The mathematics teachers who were attending this research stated that there are some problems in training gifted students about starting times and teaching hours. These problems effected technology usage skills, therefore they stated that there should be some changes in gifted children education in Turkey. For these reasons, it can be useful to make a separate school in which gifted students spend all their time in these centers, not like going after their compulsory education. Therefore some important problems about training gifted students can be prevented. In addition, as for the results of research that educators who want to design appropriate activities considering the needs of gifted students, can take advantage of the potential of designbased research methods. On the other hand, in addition to appropriateness of an activity for the gifted, it is very important to know how to present this activity to gifted students. This research showed that the data can be obtained by desing-based research like in this research. 